\title{
Heterogeneity in Bipolar II Disorder Treatments: A Literature Review
}

Diego F Tavares ${ }^{1,2^{*}}$, Doris H Moreno ${ }^{1}$ and Ricardo A Moreno ${ }^{1}$

${ }^{1}$ Faculty of Medicine, Department and Institute of Psychiatry, Mood Disorders Unit (GRUDA), University of São Paulo, São Paulo, Brazil

${ }^{2}$ Department of Psychiatry, Bipolar Disorders Program (PROTAB), ABC Medical School, São Paulo, Brazil

\begin{abstract}
Introduction: We reviewed the literature to examine: (1) Aspects related to the diagnostic boundaries of mild forms of bipolar disorder (BD); (2) The controversies related to the diagnostic criteria of phasic hypomania and chronic hypomania; (3) Aspects related to the treatment and the use of antidepressants in mild forms of BD. topics.

Methods: Comprehensive computer literature search to find relevant peer reviewed articles related to this these

Results: Mild forms of BD suffer from the big problem of misdiagnosis with recurrent and treatment resistant major depressive disorder. One factor explaining which explains this, at least in part, is the fact that the current diagnostic criteria for hypomania, as it is concepted today, are is still quite restrictive and often sensitive only to more exuberant clinical pictures, such as mild manias. In addition to this, the use of antidepressants in the mild cases of BD will hardly aid in diagnosis, because strong mood swings are not enough to permit diagnosis (leading to the emergence of hypomania) and are not common in these mild forms. The most important question in the treatment of BD II is not the acute treatment of hypomania itself but the recognition that they exist and influence the recurrence recurrence of depressive episodes.

Conclusion: This review showed the fragility and low sensitivity of the current criteria for diagnosis and management of BD II. Clinical trials evaluating the treatment of these conditions cannot be generalizable generalized for all the subpopulation of BD II we see in clinical practice.
\end{abstract}

Keywords: Bipolar II disorder; Other bipolar and related disorders; Hypomania criteria; Pharmacological treatment

\section{Introduction}

Bipolar disorder (BD) is a complex psychiatric disorder linked to brain dysregulation of mood, energy, impulses and thinking brain areas. The manifestations that characterize the disease are: Maniac episodes in bipolar I disorder (DB I), with or without depressive episodes; and hypomania plus major depressive episodes in bipolar II disorder (BD II) [1]. The cumulative incidence of $\mathrm{BD}$ at age 50 in the most recent longitudinal study was $1.21 \%$ for BD I and $2.22 \%$ for BD II [2].

The most natural course of both BDI or BDII is the occurrence of depressive episodes as first life episodes, so it is invariably first diagnosed as major depressive disorder (MDD). Previous research has shown that the mean time from a diagnosis of MDD to BD is about 8 to 10 years [3-5]. Antidepressant treatment resistance is one of the most common predictors of diagnostic conversion from MDD to BD [6,7]. Another common risk factor for the diagnostic modification of MDD for $\mathrm{BD}$ is the early onset of depression, that is, before the age of 30 years $[8,9]$. Findings from recent research suggested that an earlier diagnosis of depression is related to a longer delay in conversion to $\mathrm{BD}$ [5] [10]. Moreover, depressive episodes prior to 25-years-old nearly triples the likelihood of a subsequent diagnosis of BD [11].

Although a delay in the diagnosis of bipolar disorder is common, the severe form with episodes of mania, in BD I, is unlikely to go unnoticed and adequate treatment is often and soon implemented. In contrast, mild forms, such as BD II, suffer from an even greater problem, misdiagnosis with MDD and the use of antidepressants for long periods, delaying the use of mood stabilizing drugs that would be better suited to better treatment of $\mathrm{BD}$ in long term, preventing recurrence and severe disease presentations such as mixed states and rapid cycling [12]. In addition to this, in contrast to classic forms in which the use of antidepressants in a major depressive episodes (MDE) usually leads to mood swings that lead to the appropriate diagnosis of $\mathrm{BD}$, in mild forms the mood usually does not become polarized to pure (euphoric mood) or hard forms (mania), but usually swings to mixed- states or rapid-cycling conditions that may be missed by the clinician for long years [13].

The BII diagnosis is currently stated in the identification of episodic hypomania lasting at least 4 days and with a hypomanic syndrome that presents the same symptom presentation as mania but without psychotic symptoms, with no impairment in most spheres of life and without sufficient intensity to carry out hospitalization [14]. However, the hypomania course in BD II is often chronic and not episodic like those of the current diagnostic criteria. Hypomanic symptoms in these cases are present in insidious course and often are obscured by traits of the individual's temperament [15-17]. Another important aspect is the phenomenological presentation of the mood episode in BD II. Frequently, a classical hypomania presentation (pure/euphoric mood) is expected, either spontaneous or induced by treatments with antidepressant substances, but it is frequently missed that hypomania is often mixed, that is, with the simultaneous occurrence of depressive symptoms and the failure to identify it will lead to a delay in the appropriate diagnosis and a consequent failure in the proposed treatments [17].

Therefore, the main goal of this literature review is to examine aspects related to great heterogeneity in the treatment of BD II due to these two factors: the diagnosis (phasic course vs. chronic course) and the course (pure $v s$. mixed episodes) of the hypomanias.

*Corresponding author: Diego F Tavares, Faculty of Medicine, Department and Institute of Psychiatry, Mood Disorders Unit (GRUDA), University of São Paulo, São Paulo, Brazil, Tel/Fax: +55 11 2661-6648; E-mail: diego.tavares@hc.fm.usp.br

Received November 28, 2018; Accepted December 20, 2018; Published December 24, 2018

Citation: Tavares DF, Moreno DH, Moreno RA (2018) Heterogeneity in Bipolar II Disorder Treatments: A Literature Review. Brain Disord Ther 7: 250. doi: 10.4172/2168-975X.1000250

Copyright: (c) 2018 Tavares DF, et al. This is an open-access article distributed under the terms of the Creative Commons Attribution License, which permits unrestricted use, distribution, and reproduction in any medium, provided the original author and source are credited. 


\section{Literature Review}

A comprehensive computer literature search of PubMed/MEDLINE, Cochrane Central Register of Controlled Trials (CENTRAL), Embase, PsycINFO, and CINAHL databases was carried out to find relevant peer reviewed articles published in any language until May 31, 2017 on bipolar II disorder OR other specified bipolar and related disorders OR bipolar not otherwise specified, cross-referenced with the terms 'bipolar', 'depression', 'major depressive episode', 'bipolar spectrum', 'hypomania, 'rapid cycling,' 'mixed features', 'mixed depression', 'mixed mania', 'mixed hypomania, 'major depressive disorder'. Furthermore, the terms 'diagnosis', 'treatment', 'response', 'remission', 'treatment resistance' were matched with the main terms of the search. Articles were selected from systematic reviews (with or without meta-analyses), randomized clinical trials (RCTs), open trials and longitudinal studies, and the results were summarized below.

\section{Results}

We hypothesize that heterogeneity in treatment options for BD II occurs due to 2 factors: the great variability in the diagnosis of hypomania (phasic course versus chronic course) and the great variability of clinical course of the disease (pure mood episodes versus mixed episodes). Therefore, treatment should take these differences into account as there will be an impact on treatment if we are dealing with very different diagnosis criteria of hypomania and different courses, namely:

1) Recurrent depressive episodes interspersed with phasic pure hypomanias (Euphoric mood).

2) Recurrent depressive episodes interspersed with chronic subsyndromical hypomanic symptoms.

3) BDII with spontaneous mixed states (Mixed depression and/or mixed hypomanias).

\section{4) BDII with antidepressant-induced hypomanias.}

The most recent treatment guidelines [18-20] do not take these subpopulation differences into account precisely because RCTs conducted in $\mathrm{BD}$ II cover only subpopulations with phasic pure hypomanias described at DSM-5 guidelines which corresponds in practice to a "mild mania" since it comprises the same symptoms of mania but in lesser intensity and of phasic occurrence. Interestingly, two small RCTs have evaluated treatment options for acute phasic hypomania. The first McElroy et al. [21], a small double-blind and placebo-controlled RCT $(n=39)$ showed that quetiapine (average daily dose $=232 \mathrm{mg}$ ) had a marginally greater rate of reduction in mean total YMRS in a hypomania "mild mania-like" score than patients receiving placebo $(\mathrm{p}=0.06)$ after 8 -weeks. The second one McElroy et al. [22] a double-blind and placebo-controlled RCT $(n=60)$ showed that divalproex ER (begun at $15 \mathrm{mg} / \mathrm{kg} / \mathrm{d}$ and titrated to a maximum of $30 \mathrm{mg} / \mathrm{kg} / \mathrm{d}$ ) had a significantly greater rate of reduction in mean total YMRS in a hypomania "mild mania-like" score than the placebo group ( $p=0.024)$ after 8-weeks. Due to the methodological limitations of RCT in hypomania, since the most common presentation is transient and difficult to recognize in real time, it is difficult to formulate evidencebased treatment recommendations for phasic hypomanias.

Clinical practice suggests that medications that are effective in mania are effective in treating hypomanic symptoms. However, the most important question in BD II treatment is not the acute treatment of hypomania itself but the recognition that they exist and recur and that their presence in the natural history of the disease are related to the high recurrence of depressive episodes in BD II. The understanding and treatment of bipolar disorder as a whole have grown, so that treatments should cover the improvement of symptoms of the acute phase, but clinicians should always bear in mind the longitudinal course of the disease and the disease as a whole [23].

Recurrent depressive episodes are the most common symptomatic manifestations of BD II, and often severe and difficult to treat with a high therapeutic resistance index [24]. So far, quetiapine doses of 300 $\mathrm{mg}$ a day and $600 \mathrm{mg}$ a day is the only first option in BD II depression treatment [25-28]. However, most RCTs use mixed samples of BD I and BII because BD II literature is scarce. Lurasidone has been approved in the United States by the Food and Drug Administration (FDA) for the treatment of BD I depression and recent studies corroborates this findings [29-31]. Although promising, no study evaluated the hole of lurasidone in BD II.

Comparing to BDI, we observe that the efficacy of antidepressants (AD) in BD II seems to be modest and that the benefits are greater at the beginning of the course of the disease, with worse efficacy in chronic disease and mixed presentation where the treatment resistance is high [32,33]. AD have well established efficacy in unipolar depression and this has defined such molecules as antidepressants as they appear to have this "class effect" in MDE. However, such "class effect" does not appear to be present in all subtypes of bipolar depression [34]. One of the oldest double-blind and placebo-controlled study-regarded the $\mathrm{AD}$ use in anergic depression (BD I=10, BD II=19 and recurrent $M D D=11$ ) and reported superiority of tranylcypromine versus placebo and suggested that tranylcypromine could be efficacious in bipolar I and II depression since anergic depression most typically occurs in $\mathrm{BD}$ and in pseudo unipolar affective illnesses [35]. Since then, several studies have demonstrated the acute efficacy of AD in bipolar II depression, however, the interpretation of some of these results is hampered by the concomitant use of lithium or antipsychotics or other methodological problems [36-40].

There is a false concept that AD may show preferential efficacy and safety among patients with $\mathrm{BD}$ II than $\mathrm{BD}$ I and that the use of $\mathrm{AD}$ in $\mathrm{BD}$ II, even in monotherapy, would rarely -produce hypomanias. However, as mentioned previously, there is a great negligence about the mixed episodes (mixed depression and mixed hypomania) and the treatment resistance associated to AD's use in $\mathrm{BD}$ II [33]. In a recent RCT, patients in acute major depressive episodes (BD I= 21 and $\mathrm{BD} I \mathrm{I}=49$ ) were treated with $\mathrm{AD}$ plus mood stabilizers to euthymia, sustained for 2 months and then randomized openly to continue or discontinue $\mathrm{AD}$ for up to 3 years. In the follow-up both subgroups showed improvement in depressive episodes frequency with $\mathrm{AD}$ continuation, but contrary to the hypothesis, more improvement was seen in BD I than in BD II. Subjects with $\mathrm{BD}$ II who continued on $\mathrm{AD}$ had more depressive, but fewer manic/hypomanic, episodes than subjects with BD I [41]. In contrast, one open study evaluated $\mathrm{AD}$ monotherapy in 255 patients in acute major depressive episode $(\mathrm{MDD}=154, \mathrm{BD} \mathrm{I}=49$ and $\mathrm{BD} \mathrm{II}=52)$ and found that response was achieved by $65 \%$ of patients with MDD, $75 \%$ of patients with BD I and $75 \%$ with BD II without significant differences between groups and $\mathrm{AD}$-emerging switch was observed in $2.9 \%$ of patients. The authors advocate the short-term use of $\mathrm{AD}$ in bipolar depression. The results are limited to patients with pure bipolar depression (excluding those with broadly defined mixed states) [42]. One of the best-conducted studies aiming to evaluate the use of antidepressants in bipolar depression was conducted on a sample of 740 patients with bipolar depression (BDI and BD II). This study was negative for paroxetine $20 \mathrm{mg} /$ day while it was positive for quetiapine. However, paroxetine produced a significant improvement in anxiety was not effective concerning depressive symptoms [28]. 
Citation: Tavares DF, Moreno DH, Moreno RA (2018) Heterogeneity in Bipolar II Disorder Treatments: A Literature Review. Brain Disord Ther 7: 250. doi: $10.4172 / 2168-975 X .1000250$

Page 3 of 7

In clinical practice the use of antidepressants in bipolar depression is often inevitable because:

(1) The first episodes of the disease are generally depressive and during the whole course the majority of episodes will be depressive.

(2) The only pharmacotherapy alternatives are atypical antipsychotics, anticonvulsants or lithium, none of which were developed specifically to treat depression per se.

(3) In many instances antidepressants are found to be effective and of sufficient benefit to warrant a real life trial [43].

However, in practice the problem antidepressants face is that they are not seemingly as effective in treating bipolar II depression as they are in treating major depression and the outcome is largely unpredictable because bipolar II depression is a very heterogeneous group of diseases. When these differences are not taken into account what we observe in clinical practice is that the response to antidepressants in BII bipolar depression is especially erratic, that is, we cannot predict the response in each patient individually in clinical frame (Figure 1).

\section{Temporary efficacy and loss of effect}

The antidepressant demonstrates adequate efficacy and is capable of producing response ( $<50 \%$ of symptoms) and in some cases remission (complete resolution of symptoms) but after some variable period of time the $\mathrm{AD}$ effect seems to disappear, and the levels of depression return to what it had previously presented. AD tachyphylaxis (also known as antidepressant tolerance, antidepressant "poop-out," or "breakthrough" depression) describes a recurrent depressive episode that is a form of relapse and was best described in MDD. As a loss of response, $\mathrm{AD}$ tachyphylaxis is distinct from a non-response to treatment (resistance) or a partial (inadequate) AD response. Previous exposure to long-term $\mathrm{AD}$ may be a factor in the development of antidepressant drug tolerance and it has been reported that depressed patients with "true" antidepressant tachyphylaxis may be less responsive to new $\mathrm{AD}$ treatment interventions. This is a common practice in BD II patients where many trials of $\mathrm{AD}$ are the common practice. It is speculated that tachyphylaxis is a common phenomenon in BD II and that it comprises a mechanism of defense of the nervous system against the continuous stimulation produced by $\mathrm{AD}$ [44]. The National Institute of Mental Health Collaborative Depressive Study reported that the rate of $\mathrm{AD}$ tachyphylaxis in MDD was $25 \%$. In this 20-year follow-up study of $103 \mathrm{MDD}$ patients, AD tachyphylaxis occurred in 43 of the 171 subsequent recurrent depressive episodes (25\%) experienced by these patients [45]. It is important to consider possible confounding factors that might obscure the identification of true $\mathrm{AD}$ tachyphylaxis. For instance, patients with BD II may appear to lose their AD response but could actually be cycling through different stages of illness severity. Some authors believe that tachyphylaxis is in reality a mere cycling phenomenon unrecognized by the clinician, such as a patient who has cycled from depression to a mild pure (euphoric) hypomania and then returned for depression, so that it was believed to have been a loss of $\mathrm{AD}$ response when in fact there was a mere cycling between mood states [44].

\section{No efficacy}

Although for a subset of patients the use of $\mathrm{AD}$ appears to be effective and innocuous in terms of the complication of BD, to others they simply do not improve or even worse the status of depression. Even recent meta-analyses into this concern provide inconsistent findings regarding the efficacy of antidepressants in bipolar depression [46,47].

\section{Mixed depression induced by AD}

In some instances, even at therapeutic dosage, $\mathrm{AD}$ administration can cause a treatment-emergent affective switch (TEAS). The BRIDGE study suggested that BD exists on a continuum [48], and the new DSM5 criteria for mixed states are less restrictive than DSM-IV-TR and also recognize the occurrence of mixed symptoms in the context of BD II and MDD [14]. The DSM-5 introduced specifiers that can be applied to the manic or depressive poles. A depression with mixed features would be a predominantly depressive mood picture (depressed mood,

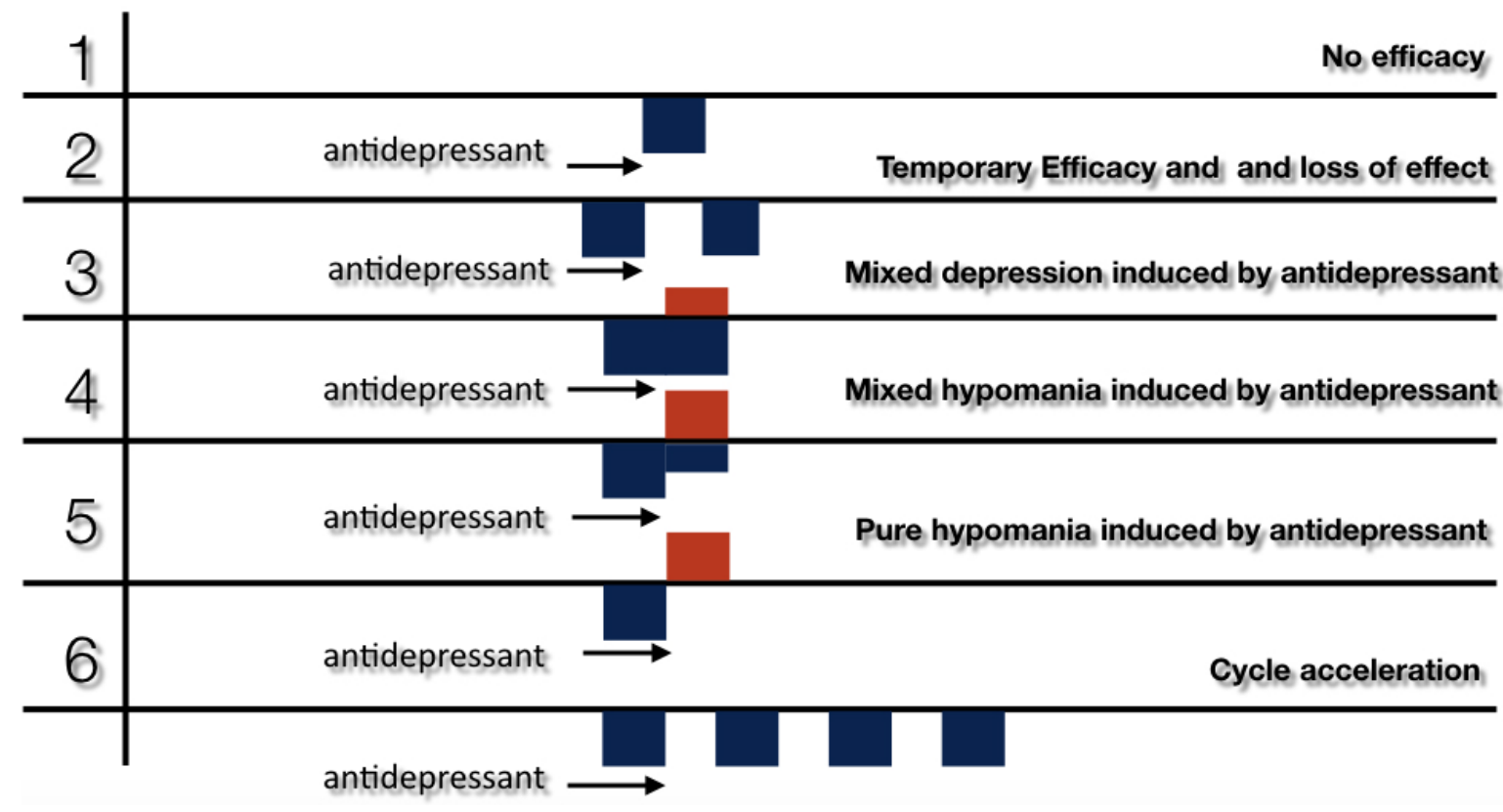

Figure 1: Responses to antidepressants in BII bipolar depression. 
guilt, worthlessness, ideas of death or suicide, anergy and anhedonia, for example) with at least 3 manic symptoms: decreased need for sleep; grandiosity; increased targeted activity; greater involvement in potentially risky ventures; speech pressure or flight of ideas. Although symptoms of rapid thoughts, irritability and distractibility are very common in mixed depressive episodes and may represent cardinal symptoms of this syndrome they were not included in the DSM-5 criteria because they were judged to be symptoms common to both poles (manic and depressive) at the same instance [14]. Some authors criticize this arbitrary exclusion and advocate that all 3 symptoms that have been excluded from DSM-5 may be cardinal features of mixed states, as they 'dip' into depressive symptoms to create a real mixed state [49]. In a study of a newer atypical antipsychotic, lurasidone, for MDD with mixed symptoms. They found benefit for lurasidone versus placebo for the defined group over the 6-week study; the authors reported on which symptoms were most frequently observed. About two-thirds (65\%) of patients met the entry criteria of 2 mixed symptoms, while the remainder otherwise met DSM-5 criteria for the mixed feature specifier $(35 \%)$. Of all patients $(n=209)$, about $67 \%$ reported flight of ideas, $61 \%$ pressured speech, $41 \%$ decreased need for sleep, $28 \%$ increased energy or activity, $18 \%$ elevated or expansive mood periodically, $16 \%$ increase in impulsive behavior, and $7 \%$ inflated self-esteem or grandiosity. By comparison for overlapping symptoms, $57 \%$ reported irritability, 59\% distractibility, and 37\% psychic agitation [50]. Apart from this, it is important to be aware of the occurrence of manic-pole symptoms in depression after the use of the antidepressant. The presence of mixed characteristics has been associated with worse clinical outcomes (anxiety, anguish, despair, suffering, etc), higher rate of comorbidity (personality disorders, substance use disorders), more relapse and greater risk of suicide in $\mathrm{BD}[51,52]$.

The International Society of bipolar disorder (ISBD) Task Force comprising 67 experts from around the world used the Delphi method to develop consensus. The report acknowledged the widespread use of antidepressants in the treatment of bipolar depression but at the same noted the weak evidence base for their efficacy and safety. A paucity of data limited the recommendations of the task force, which noted that some patients with bipolar may benefit from antidepressants and that regarding side effects selective serotonin reuptake inhibitors were less likely to precipitate switching than tricyclic antidepressants and dual action agents [53]. There are no medications approved by FDA for the treatment of MDD or BD II depression episode with mixed features. There is some concern as to the specificity of this diagnosis, and further studies will be needed to resolve this issue. The question of whether the medications that patients respond to during a MDE with mixed features are different than those for a pure MDE await future studies. While some studies suggest no negative impact of antidepressants on those with MDE with mixed features, others suggest the opposite. In an intuitive way, from extrapolation of findings from BD I to BD II and now from BD II to MDD with mixed features it is possible that patients with mixed depression benefit from the association of a mood stabilizer to the $\mathrm{AD}$ and in some cases $\mathrm{AD}$ interruption and treatment of depression with supposedly effective antipsychotics in bipolar depression (quetiapine or lurasidone). In particular, the question remains whether greater treatment resistance is conferred by mixed features as defined by DSM-5 [54-56].

\section{Mixed hypomania induced by AD}

Since DSM-IV and DSMIV-TR diagnostic guidelines have already admitted the existence of manic episodes with overlapping depressive symptoms and this condition was called a "mixed state" that was nothing more than an episode of mania with some or all of the depressive symptoms associated. As manic episodes were only characteristic of BD I, the mixed state was usually an inherent frame of BD I $[57,58]$. The DSM-5 introduced a specifier that can be applied to manic or hypomanic episodes (three or more depressive symptoms): Dysphoric mood (aggressiveness, angry, short-tempered, impatient, quarrelsome); depressed mood (sadness, guilt, worthlessness, hopelessness); psychomotor slowing; loss of interest and pleasure; fatigue or anergy; thoughts of death; ideas or suicide attempts [59].

So far, mixed episodes have been combined with pure manic episodes in RCTs and results have been reported together. Only a few papers, usually post-hoc analyses, report the results concerning mixed episodes separately. Unfortunately, all data on mixed episodes stem from trials of acute mania and there are no RCTs that have evaluated mixed hypomania. Anti-maniac agents were effective in the treatment of the old mixed states (mixed manias): risperidone, aripiprazole, carbamazepine, ziprasidone, asenapine, olanzapine, paliperidone and valproate [60-67]. One study for quetiapine failed to demonstrate efficacy on acute mixed mania [68]. Early studies demonstrated that the use of lithium alone was effective in pure mania but ineffective in mixed mania. Recent data showed that the combination of olanzapine plus lithium or valproate have positive data [69]. These findings suggest that the effect of lithium in mixed mania may occur since combined with other anti-manic agents. Most of these studies evaluated only the improvement of manic symptoms without assessing separately if there was improvement of depressive symptoms with a specific depression scale.

Among the recommendations made by the ISBD Task Force regarding antidepressant use in bipolar depression is the suggestion that $\mathrm{AD}$ should be discouraged when there is a history of emergent mania or hypomania or mixed episodes in the context of antidepressant treatment. In contrast, the next recommendation is that maintenance treatment with adjunctive antidepressant medication should be considered an option if a patient relapses into a depressive episode when antidepressant therapy is stopped [53]. Probably the treatments recommendations for mixed mania can be -extrapolated to mixed hypomania that second-generation antipsychotics, lithium as adjunctive therapy, valproate and carbamazepine are effective in treating acute mixed hypomania. One issue that needs to be improved and assessed by specific clinical trials lies in the concept that many patients have hypomanic symptoms secondary AD use and we -do not have enough evidence to decide the best recommendations in these cases: if we need to increase anti-manic mood stabilizer doses or discontinue the AD. However, it is still an issue with no evidence-based recommendations since the hypomania criteria with mixed features are quite recent.

\section{Pure hypomania induced by AD}

The issue of antidepressant-induced mood switches to hypomania or mania was better evaluated in the context of MDD. A post-hoc analysis of the BRIDGE-II-MIX study focuses on the clinical features of patients with history of antidepressant-induced hypomania/mania (AIHM) in a large international sample of patients with major depressive episode. In this - analysis, 475 patients had history of AIHM (16\%). In the MDD-AIHM group, familiarity for BD and rates of atypical features and comorbid anxiety, eating and borderline personality disorders were similar to $\mathrm{BD}$ and significantly more frequent compared to MDD group. MDD-AIHM patients had more frequently episodes and reported higher rates of treatment resistance, mood - liability and irritability following treatment with antidepressants. Frequencies of depression with mixed features and (hypo) manic symptoms were 
similar in patients of MDD-AIHM and BD groups and significantly higher in both groups than in MDD. These results strongly support the DSM-5 inclusion of MDD patients with AIHM within the rubric of BD. Some authors -suggest that MDD-AIHM may represent a specific subpopulation of $\mathrm{BD}$, particularly susceptible to $\mathrm{AD}$ effects [13].

Some subpopulations of patients with MDD and BD II are more sensitive to the occurrence of pure (euphoric/expansive) hypomania after the use of antidepressants. In contrast to mixed hypomania that would represent increased instability and worse clinical outcomes, these subpopulations may represent subgroups of milder and purer bipolar spectrum disorders and perhaps a mood stabilizer adjustment is sufficient to stabilize the condition (rather than suspending the antidepressant as in mixed states).

\section{Cycle acceleration after AD}

One recent study found that long-term continuation of antidepressants in patients with rapid cycling bipolar disorder was associated with a threefold increase in mood episodes during the first year of follow-up [70]. It is an important study because it is the first study to examine the effects of modern antidepressants in the context of a randomized clinical trial. The researchers investigated those patients with bipolar who initially responded to antidepressant treatment in conjunction with a mood stabilizer. Specifically, all 68 patients with bipolar achieved and maintained euthymia for at least 2 months and were then randomized to continue antidepressant therapy or discontinue antidepressant treatment while continuing on a mood stabilizer. The number of patients that met criteria for rapid cycling was small $(n=16)$ but most patients in this group experienced 2 to 4 depressive episodes during follow-up as compared to non-rapid cyclers who typically had few, if any, depressive episodes. Interestingly, in patients with rapid cycling bipolar disorder the long-term continuation of antidepressants resulted in a threefold increase in the rate of depressive episodes in the first year of follow-up. It is important to note that this is distinct from switching into mania or hypomania from depression and this is significant, as pointed out by the authors, because it suggests this is a separate process from rapid cycling per se. Also of significance is the fact that patients were taking mood stabilizers at baseline and that these were not protective with respect to worsening of depressive symptoms and the development of depression $[43,70]$.

\section{Discussion}

Mild forms of BD, like BD II, suffer from the big problem of misdiagnosis with recurrent and treatment resistant MDD. One factor -which explains this, at least in part, is the fact that the current diagnostic criteria for hypomania, as it is concepted today, -is still quite restrictive and often sensitive only to more exuberant and phasic episodes, that corresponds to mild phasic manias. It explains the BDII prevalence closer to BD I (1\%) [12]. In addition to this, the use of antidepressants in the mild cases will hardly aid in a correct diagnosis, because strong mood swings are not enough to permit diagnosis (leading to the emergence of mania or phasic hypomania) and are not common in these settings, although many clinicians think so.

Treatment guidelines are overly concerned with finding evidence for the treatment of different phases of BD II (acute depression, acute hypomania, maintenance phase) but forget that $\mathrm{BD}$ is a single entity with several different phases of manifestation and that treatment often segmented for specific phases may in the long time compromise the course and severity of the disease. This seems to be especially true in $\mathrm{BD}$ II where the use of antidepressants for long periods, at least for a portion of these patients, will delay the use of mood stabilizing drugs that prevents recurrence and severe disease presentations such as mixed states and rapid cycling [13].

When considering treatment options for BD II, it is important to bear in mind that this is a very heterogeneous disease particularly due to the great variability of clinical presentations. Therefore, treatment should take these differences into account as there will be an impact on treatment if we are dealing with very different BD II. Some BD II have rare hypomanias and others have -frequent episodes. Some BD II patients -present only pure episodes (depressions and euphoric hypomanias) others have mixed episodes (mixed depressions and dysphoric hypomanias). Some subpopulations of BD II patients show mixed symptoms spontaneously throughout the illness, others only in the presence of antidepressants. And finally, some BD II have a rapid cycling course and -recent research shows that in some populations of BD II patients with rapid cycling course the long-term continuation of antidepressants could result in an increase in the rate of depressive episodes in the follow-up and rapid cycling is a separated process of mixed features [70].

\section{Conclusion}

This review showed the fragility and low sensitivity of the current phasic hypomanic definition. Treatment clinical trials of these conditions are poorly generalized for daily clinical practice because the subpopulation of BD II in the current studies is more severe, in part because of the current criteria of hypomania which corresponds to a mild form of mania. Perhaps only after a review of the diagnostic criteria of BD II it will be possible to carry out more comprehensive clinical trials that can delimit the actual subpopulations of BD II and how they respond to treatment. The modification of the DSM-5 from the old "mixed state" to the new specifying "mixed features" was a major advance in the understanding of mood disorders as it will allow a better evaluation of the impact of the presence of manic symptoms on the major depressive episode of the MDD. This review has highlighted a number of important areas for further research. It is clear that large-scale RCTs on BD II are necessary to provide more robust evidence for the diagnosis and treatment of -these diseases. Furthermore, studies should investigate the presence of mixed depression in personality disorders (such as borderline personality disorders) elucidating whether many of mood episodes in other psychiatric settings would represent narrow boundaries with milder forms of $\mathrm{BD}$.

\section{Disclosures}

\section{Ethics approval and consent to participate}

Not applicable.

\section{Consent for publication}

Not applicable.

\section{Availability of data and material}

\section{Not applicable.}

\section{Competing interests}

Diego Freitas Tavares worked as a speaker and produced scientific material during the last two years for the following companies: Cristália and Aché. Doris Hupfeld Moreno worked as a speaker and produced scientific material during the last two years for the following companies: Abott and Aché. Ricardo Alberto Moreno acted as a consultant -, received honoraria or scientific educational grant funding or conducted clinical research sponsored by companies with developments in the area of bipolar and depressive disorders (Servier, Jansen, Daiichi Sankyo Brasil Farmacêutica Ltda., Grupo EMS, Ache, Cristália, Torrent, Abbott, GlaxoSmithKline, Pfizer). He Receives research grants from the Research Foundation Support 
Citation: Tavares DF, Moreno DH, Moreno RA (2018) Heterogeneity in Bipolar II Disorder Treatments: A Literature Review. Brain Disord Ther 7: 250. doi: $10.4172 / 2168-975 X .1000250$

Agency of the State of Sao Paulo, Brazil (FAPESP) and Receives a research productivity grant from the National Research Council - Brazil (CNPq).

\section{Funding}

Not applicable.

\section{Authors' contributions}

Diego Freitas Tavares, Ricardo Alberto Moreno e Doris Hipfeld Moreno have all wrote together and reviewed the article.

\section{Acknowledgements}

Not applicable.

\section{References}

1. Diler RS, Goldstein TR, Hafeman D, Rooks BT, Sakolsky D, et al. (2017) Characteristics of depression among offspring at high and low familial risk of bipolar disorder. Bipolar Disord 19: 344-352.

2. Angst J, Paksarian D, Cui L, Merikangas KR, Hengartner MP, et al. (2016) The epidemiology of common mental disorders from age 20 to 50 : Results from the prospective Zurich cohort study. Epidemiol Psychiatr Sci 25: 24-32.

3. Hirschfeld RM, Lewis L, Vornik LA (2003) Perceptions and impact of bipolar disorder: How far have we really come? Results of the national depressive and manic-depressive association 2000 survey of individuals with bipolar disorder. J Clin Psychiatry 64: 161-174.

4. Ghaemi SN, Ko JY, Goodwin FK (2002) "Cade's disease" and beyond: Misdiagnosis, antidepressant use and a proposed definition for bipolar spectrum disorder. Can J Psychiatry 47: 125-134.

5. Fritz Russell AM, Allwang C, Kuiper S, Lampe L, Malhi GS, et al. (2017) Is a delay in the diagnosis of bipolar disorder inevitable?. Bipolar Disord 19: 396-400.

6. Bukh JD, Andersen PK, Kessing LV (2016) Rates and predictors of remission, recurrence and conversion to bipolar disorder after the first lifetime episode of depression: A prospective 5-year follow-up study. Psychol Med 46: 1151-1161.

7. Dudek D, Siwek M, Zielińska D, Jaeschke R, Rybakowski J (2013) Diagnostic conversions from major depressive disorder into bipolar disorder in an outpatient setting: Results of a retrospective chart review. J Affect Disord 144: 112-115.

8. Tondo L, Visioli C, Preti A, Baldessarini RJ (2014) Bipolar disorders following initial depression: Modeling predictive clinical factors. J Affect Disord 167: 44-49.

9. Suominen K, Mantere O, Valtonen H, Arvilommi P, Leppämäki S, et al. (2007) Early age at onset of bipolar disorder is associated with more severe clinical features but delayed treatment seeking. Bipolar Disord 9: 698-705.

10. Rybakowski JK, Dudek D, Pawlowski T, Lojko D, Siwek M, et al. (2012) Use of the hypomania checklist-32 and the mood disorder questionnaire for detecting bipolarity in 1,051 patients with major depressive disorder. European Psychiatry 27: $577-581$.

11. Rybakowski JK, Suwalska A, Lojko D, Rymaszewska J, Kiejna A, et al. (2007) Types of depression more frequent in bipolar than in unipolar affective illness: Results of the Polish DEP-BI study. Psychopathology 40: 153-158.

12. Kohler S, Friedel E, Stamm T (2017) Rapid cycling in bipolar disorders: Symptoms, background and treatment recommendations. Fortschr Neurol Psychiatr 85: 199-211.

13. Barbuti M, Pacchiarotti I, Vieta E, Azorin JM, Angst J, et al. (2017) Antidepressant-induced hypomania/mania in patients with major depression: Evidence from the BRIDGE-II-MIX study. J Affect Disord 219: 187-192.

14. Association AP (2014) Manual diagnóstico e Estatístico de Transtornos Mentais: Artmed Editora DSM p: 5.

15. Malhi GS, Chengappa KR, Gershon S, Goldberg JF (2010) Hypomania: Hype or mania?. Bipolar Disord 12: 758-763.

16. Bobo WV (2017) The diagnosis and management of bipolar i and ii disorders: Clinical practice update. Mayo Clin Proc 92: 1532-1551.

17. Parker G, Tavella G, Macqueen G, Berk M, Grunze H, et al. (2018) Revising diagnostic and statistical manual of mental disorders, fifth edition, criteria for the bipolar disorders: Phase I of the AREDOC project. Aust NZ J Psychiatry p: 4867418808382
18. Yatham LN, Kennedy SH, Parikh SV, Schaffer A, Beaulieu S, et al. (2013) Canadian Network for Mood and Anxiety Treatments (CANMAT) and International Society for Bipolar Disorders (ISBD) collaborative update of CANMAT guidelines for the management of patients with bipolar disorder: Update 2013. Bipolar Disord 15: 1-44.

19. Goodwin GM, Haddad PM, Ferrier IN, Aronson JK, Barnes T, et al. (2016) Evidence-based guidelines for treating bipolar disorder: Revised third edition recommendations from the British Association for Psychopharmacology. J Psychopharmacol 30: 495-553.

20. Fountoulakis KN, Grunze H, Vieta E, Young A, Yatham L, et al. (2016) The International College of Neuro-Psychopharmacology (CINP) treatment guidelines for bipolar disorder in adults (CINP-BD-2017), Part 2: Review, grading of the evidence, and a precise algorithm. Int J Neuropsychopharmacol 20: $180-195$.

21. McElroy SL, Martens BE, Winstanley EL, Creech R, Malhotra S, et al. (2010) Placebo-controlled study of quetiapine monotherapy in ambulatory bipolar spectrum disorder with moderate-to-severe hypomania or mild mania. J Affect Disord 124: 157-163

22. McElroy SL, Martens BE, Creech RS, Welge JA, Jefferson L, et al. (2010) Randomized, double-blind, placebo-controlled study of divalproex extended release loading monotherapy in ambulatory bipolar spectrum disorder patients with moderate-to-severe hypomania or mild mania. J Clin Psychiatry 71: 557565.

23. Missio G, Moreno DH, Fernandes F, Bio DS, Soeiro-de-Souza MG, et al. (2013) The ARIQUELI study: Potentiation of quetiapine in bipolar I non-responders with lithium vs. aripiprazole. Trials 14: 190.

24. McCloud TL, Caddy C, Jochim J, Rendell JM, Diamond PR, et al. (2017) Ketamine and other glutamate receptor modulators for depression in bipolar disorder in adults. Cochrane Database Syst Rev 38: 526-527.

25. Calabrese JR, Keck Jr PE, Macfadden W, Minkwitz M, Ketter TA, et al. (2005) A randomized, double-blind, placebo-controlled trial of quetiapine in the treatment of bipolar I or II depression. Am J Psychiatry 162: 1351-1360.

26. Thase ME, Macfadden W, Weisler RH, Chang W, Paulsson B, et al. (2006) Efficacy of quetiapine monotherapy in bipolar I and II depression: A doubleblind, placebo-controlled study (the BOLDER II study). J Clin Psychopharmacol 26: 600-609.

27. McElroy SL, Weisler RH, Chang W, Olausson B, Young AH, et al. (2010) A double-blind, placebo-controlled study of quetiapine and lithium monotherapy in adults in the acute phase of bipolar depression (EMBOLDEN I). J Clin Psychiatry 71: 150-162.

28. McElroy SL, Weisler RH, Chang W, Olausson B, Paulsson B, et al. (2010) A double-blind, placebo-controlled study of quetiapine and paroxetine as monotherapy in adults with bipolar depression (EMBOLDEN II). J Clin Psychiatry 71: 163-174.

29. Ketter TA, Sarma K, Silva R, Kroger H, Cucchiaro J, et al. (2016) Lurasidone in the long-term treatment of patients with bipolar disorder: A 24-week open-label extension study. Depress Anxiety 33: 424-434.

30. Ketter TA, Sarma K, Silva R, Kroger H, Cucchiaro J, et al. (2016) Lurasidone adjunctive with lithium or valproate for bipolar depression: A placebo-controlled trial utilizing prospective and retrospective enrolment cohorts. J Psychiatr Res 78: 86-93.

31. Fornaro M, Stubbs B, De Berardis D, Perna G, Valchera A, et al. (2016) Atypical antipsychotics in the treatment of acute bipolar depression with mixed features: A systematic review and exploratory meta-analysis of placebo-controlled clinical trials. Int J Mol Sci 17: 241.

32. Malhi GS, Bassett D, Boyce P, Bryant R, Fitzgerald PB, et al. (2015) Roya Australian and New Zealand college of psychiatrists clinical practice guidelines for mood disorders. Aust NZ J Psychiatry 49: 1087-1206.

33. Hidalgo-Mazzei D, Berk M, Cipriani A, Cleare AJ, Di Florio A, et al. (2018) Treatment-resistant and multi-therapy-resistant criteria for bipolar depression: Consensus definition. Br J Psychiatry 214: 1-9.

34. Fountoulakis KN, Gonda X, Vieta E, ZetR(2011) Class effect of pharmacotherapy in bipolar disorder: Fact or misbelief?. Ann Gen Psychiatry 10: 8.

35. Himmelhoch JM, Fuchs CZ, Symons BJ (1982) Double-blind study of tranylcypromine treatment of major anergic depression. J Nerv Ment Dis 170 628-634. 
Citation: Tavares DF, Moreno DH, Moreno RA (2018) Heterogeneity in Bipolar II Disorder Treatments: A Literature Review. Brain Disord Ther 7: 250. doi: $10.4172 / 2168-975 X .1000250$

36. Cohn JB, Collins G, Ashbrook E, Wernicke JF (1989) A comparison of fluoxetine imipramine and placebo in patients with bipolar depressive disorder. Int Clin Psychopharmacol 4: 313-322.

37. Parker G, Tully L, Olley A, Hadzi-Pavlovic D (2006) SSRIs as mood stabilizers for bipolar II disorder?: A proof of concept study. J Affect Disord 92: 205-214.

38. Li DJ, Tseng PT, Chen YW, Wu CK, Lin PY (2016) Significant treatment effect of bupropion in patients with bipolar disorder but similar phase-shifting rate as other antidepressants: A meta-analysis following the PRISMA guidelines. Medicine (Baltimore) 95: 3165.

39. Antosik-Wojcinska AZ, Stefanowski B, Swiecicki L (2015) Efficacy and safety of antidepressant's use in the treatment of depressive episodes in bipolar disorder: Review of research. Psychiatr Pol 49: 1223-1239.

40. Amsterdam JD, Lorenzo-Luaces L, Soeller I, Li SQ, Mao JJ, et al (2016) Shortterm venlafaxine $v$. lithium monotherapy for bipolar type II major depressive episodes: Effectiveness and mood conversion rate. Br J Psychiatry 208: 359365 .

41. Vohringer PA, Ostacher MJ, El-Mallakh RS, Holtzman NS, Thommi SB, et al (2015) Antidepressants in Type II vs. Type I bipolar depression: A randomized discontinuation trial. J Clin Psychopharmacol 35: 605-608.

42. Tundo A, Calabrese JR, Proietti L, De Filippis R (2015) Short-term antidepressant treatment of bipolar depression: Are ISBD recommendations useful in clinical practice?. J Affect Disord 171: 155-160.

43. Malhi GS (2015) Antidepressants in bipolar depression: Yes, no, maybe?. Evid Based Ment Health 18: 100-102.

44. Targum SD (2014) Identification and treatment of antidepressant tachyphylaxis. Innov Clin Neurosci11 11: 24-28.

45. Solomon DA, Leon AC, Mueller TI, Coryell W, Teres JJ, et al. (2005) Tachyphylaxis in unipolar major depressive disorder. J Clin Psychiatry 66: 283290.

46. Sidor MM, Macqueen GM (2011) Antidepressants for the acute treatment of bipolar depression: A systematic review and meta-analysis. J Clin Psychiatry 72: $156-167$.

47. Vazquez G, Tondo L, Baldessarini RJ (2011) Comparison of antidepressan responses in patients with bipolar vs. unipolar depression: A meta-analytic review. Pharmacopsychiatry 44: 21-26.

48. Angst J, Azorin JM, Bowden CL, Perugi G, Vieta E, et al. (2011) Prevalence and characteristics of undiagnosed bipolar disorders in patients with a major depressive episode: The BRIDGE study. Arch Gen Psychiatry 68: 791-799.

49. Malhi GS, Fritz K, Allwang C, Burston N, Cocks C, et al. (2016) Are manic symptoms that 'dip' into depression the essence of mixed features?. J Affect Disord. 192: 104-108.

50. Suppes T, Silva R, Cucchiaro J, Mao Y, Targum S, et al. (2015) Lurasidone for the treatment of major depressive disorder with mixed features: A randomized, double-blind, placebo-controlled study. Am J Psychiatry 173: 400-407.

51. Seo HJ, Wang HR, Jun TY, Woo YS, Bahk WM (2016) Factors related to suicidal behavior in patients with bipolar disorder: The effect of mixed features on suicidality. Gen Hosp Psychiatry 39: 91-96.

52. Shim IH, Woo YS, Bahk WM (2015) Prevalence rates and clinical implications of bipolar disorder "with mixed features" as defined by DSM-5. J Affect Disord 173: 120-125.

53. Pacchiarotti I, Bond DJ, Baldessarini RJ, Nolen WA, Grunze H, et al. (2013)
The International Society for Bipolar Disorders (ISBD) task force report on antidepressant use in bipolar disorders. Am J Psychiatry 170: 1249-1262.

54. Perlis RH, Cusin C, Fava M (2014) Proposed DSM-5 mixed features are associated with greater likelihood of remission in out-patients with major depressive disorder. Psychol Med 44: 1361-1367.

55. Perugi G, Angst J, Azorin JM, Bowden CL, Mosolov S, et al. (2015) Mixed features in patients with a major depressive episode: The BRIDGE-II-MIX study. J Clin Psychiatry 76: e351-358.

56. Faedda GL, Marangoni C, Reginaldi D (2015) Depressive mixed states: A reappraisal of Koukopoulos' criteria. J Affect Disord 176: 18-23.

57. Association AP (1996) DSM-IV: Manual de diagnóstico e estatística das perturbações mentais 2: 1

58. Association AP (2002) Manual diagnóstico e estatístico de transtornos mentais: Texto revisado (DSM-IV-TR): Artmed.

59. Association AP (2003) Diagnostic and statistical manual of mental disorders (DSM-5®): American Psychiatric Pub

60. Suppes T, Eudicone J, McQuade R, Pikalov III A, Carlson B (2008) Efficacy and safety of aripiprazole in subpopulations with acute manic or mixed episodes of bipolar I disorder. J Affect Disord 107: 145-154.

61. Weisler RH, Kalali AH, Ketter TA (2004) A multicenter, randomized, doubleblind, placebo-controlled trial of extended-release carbamazepine capsules as monotherapy for bipolar disorder patients with manic or mixed episodes. J Clin Psychiatry 65: 478-484.

62. Keck Jr PE, Versiani M, Potkin S, West SA, Giller E, et al. (2003) Ziprasidone in Mania study group. Ziprasidone in the treatment of acute bipolar mania: $A$ three-week, placebo-controlled, double-blind, randomized trial. Am J Psychiatry 160: 741-748.

63. Mclntyre RS, Cohen M, Zhao J, Alphs L, Macek TA, et al. (2009) A 3-week, randomized, placebo-controlled trial of asenapine in the treatment of acute mania in bipolar mania and mixed states. Bipolar Disord 11: 673-686.

64. Baker RW, Tohen M, Fawcett J, Risser RC, Schuh LM, et al. (2003) Acute dysphoric mania: Treatment response to olanzapine vs. placebo. J Clin Psychopharmacol 23: 132-137.

65. Bowden CL, Swann AC, Calabrese JR, Rubenfaer LM, Wozniak PJ, et al (2006) A randomized, placebo-controlled, multicenter study of divalproex sodium extended release in the treatment of acute mania. J Clin Psychiatry 67: 1501-1510

66. Citrome $L$ (2012) Lurasidone in schizophrenia: New information about dosage and place in therapy. Adv Ther 29:815-825.

67. Berwaerts J, Xu H, Nuamah I, Lim P, Hough D (2012) Evaluation of the efficacy and safety of paliperidone extended-release in the treatment of acute mania: $A$ randomized, double-blind, dose-response study. J Affect Disords 136: 51-60.

68. Cutler AJ, Datto C, Nordenhem A, Minkwitz M, Acevedo L, et al. (2011) Extended-release quetiapine as monotherapy for the treatment of adults with acute mania: A randomized, double-blind, 3-week trial. Clin Ther 33: 1643 1658.

69. Baker RW, Brown E, Akiskal HS, Calabrese JR, Ketter TA, et al. (2004) Efficacy of olanzapine combined with valproate or lithium in the treatment of dysphoric mania. Br J Psychiatry 185: 472-478.

70. El-Mallakh RS, Vöhringer PA, Ostacher MM, Baldassano CF, Holtzman NS, et al. (2015) Antidepressants worsen rapid-cycling course in bipolar depression: A STEP-BD randomized clinical trial. J Affect Disord 184: 318-321. 